\title{
Revisitando o modelo processual de análise de políticas públicas com base nas relações entre Estado e Sociedade
}

\author{
Patrícia Aparecida Ferreira \\ Edgard Alencar ${ }^{2}$ \\ José Roberto Pereira ${ }^{3}$
}

\begin{abstract}
Resumo: O trabalho procura discorrer sobre alguns aspectos transversais na análise de política pública sob a perspectiva do modelo processual (ciclo de política pública), tais como: instituições, fragmentação, descentralização, participação, saber técnico e saber local. O modelo processual é enfocado não apenas como uma sistematização de fases administrativas (formulação, implementação e avaliação), mas considerados aspectos de diferentes naturezas. Portanto, este trabalho propõe que o modelo processual seja compreendido como uma construção social, na qual as políticas emergem de um processo interativo entre Estado e Sociedade. Além disso, rompe-se com a ideia de que a análise de políticas públicas abrange apenas preceitos da perspectiva tecnoburocrática, mas, sobretudo, instiga iniciativas de formação da esfera pública e emancipação social, servindo como referência para a gestão social de políticas públicas.
\end{abstract}

Palavras-chave: Ciclo de política pública. Estado. Sociedade.

Abstract: The paper tries to discuss some aspects that are transversal in the public policy analysis from the perspective of the procedural model (public policy cycle), such as: institutions, fragmentation, decentralization, participation, technical knowledge and local knowledge. The process model is focused not only as a systematization of administrative phases (formulation, implementation and evaluation), but are considered aspects of different natures. Therefore, this work proposes that the procedural model be understood as a social construction, in which the policies emerge from an interactive process between State and Society. Moreover, it breaks with the idea that the analysis of public policies only covers precepts of the technobureaucratic perspective, but above all, it instigates initiatives of formation of the public sphere and social emancipation, serving as reference for the social management of public policies.

Keywords: Public policy cycle. State. Society.

\section{Introdução}

Como os diversos objetos de estudos nas ciências sociais, a análise de política pública é muito ampla e envolve várias formas de abordagens e modelos (CAVALCANTE; ARRUDA, 2016). Autores como Barcelos (2013) destacam o fenômeno "políticas públicas", com base na síntese de duas grandes orientações teóricas: as abordagens institucionais e as de escolha racional. Na visão de Secchi (2016), a

\footnotetext{
1 Universidade Federal de Lavras. Doutorado em Administração (UFLA). Professora adjunta do Departamento de Administração e Economia. E-mail: paf@ufla.br.

${ }^{2}$ Universidade Federal de Lavras. Doutorado em Rural Social Development pela The University Of Reading e Pós-Doutorado em Metodologia de Pesquisa pela The University Of Reading. Professor titular aposentado do Departamento de Administração e Economia. E-mail: eddalencar@uol.com.br.

${ }^{3}$ Universidade Federal de Lavras. Doutorado em Sociologia pela Universidade de Brasília e pós-doutorado em Ciências Sociais pelo Centro de Estudos Sociais da Universidade de Coimbra. Professor titular aposentado do Departamento de Administração e Economia. E-mail: jrobpereira25@yahoo.com.br.
}

Página 58 Caderno de Ciências Sociais Aplicadas, Vitória da Conquista/BA, vol. 16, n 27, ano 16, p. 58-85, jan/jun 2019. 
análise de política pública apresenta duas abordagens: a racionalista e argumentativa. A racionalista tem como pressuposto a adequação dos meios aos fins desejados, a projeção de resultados e a recomendação da política pública que gere maior bem-estar social. A argumentativa propõe a participação, a discursividade, o ajuste mútuo e a harmonização dos interesses dos atores políticos para chegar a políticas públicas coletivamente construídas.

Diversos modelos conceituais são utilizados para o estudo das políticas públicas - institucional, de processo, de elite, racional, incremental, da teoria de jogos, da opção pública e sistêmico. Dye (2009) destaca que estes se originam de diferentes abordagens que, em princípio, não foram formuladas com a finalidade de estudar a política pública, mas oferecem um caminho de reflexão. Logo, esses modelos visam simplificar e esclarecer as ideias sobre políticas públicas; identificar aspectos importantes de questões político-sociais; focalizar nas características da vida política; direcionar esforços para compreender melhor tais políticas, sugerindo o que é e o que é não importante; propor explicações e prever suas consequências.

Entre os modelos conceituais que permeiam o estudo sobre políticas públicas, destaca-se o modelo de processo que designa a política pública como um ciclo fundamentado em três fases políticoadministrativas: formulação, implementação e avaliação (FREY, 2000). Há uma notória preocupação de analistas em descrever ou aplicar de forma sucessiva as fases que conformam esse ciclo como um quadro de referência para a análise de política pública sob a ótica procedimental, administrativa e racional. Ao considerar esse ciclo como uma forma de análise de políticas públicas, o analista também deve ter consciência de que aspectos de diferentes naturezas poderão ser verificados na sua utilização.

Conforme expõe Barcelos (2013), dimensões relacionadas a poder, pressão, influência, crenças, valores, ideias e visões de mundo agregam uma orientação analítica baseada no pressuposto de que a análise de políticas públicas pode ser compreendida como uma construção social. Sob essa perspectiva, este trabalho procura apresentar o modelo processual pautados em alguns aspectos presentes nas relações complexas entre o Estado e a Sociedade, tais como: instituicionais, poder, fragmentação, descentralização, participação social, saber técnico e saber local. Dessa forma, o trabalho está organizado de modo a apresentar as premissas básicas sobre política pública, alguns modelos conceituais de análise, bem como uma discussão dos aspectos que permeiam as fases de formulação, implementação e avaliação que integram o modelo de ciclo de políticas públicas. A seguir, são apresentadas algumas dicotomias que recaem sobre as reflexões em análise processual de políticas públicas, tais como o Estado e a sociedade, o saber técnico e o saber local.

Página 59 Caderno de Ciências Sociais Aplicadas, Vitória da Conquista/BA, vol. 16, n 27, ano 16, p. 58-85, jan/jun 2019. 


\section{Políticas Públicas: aspectos conceituais e análise de contexto}

As políticas públicas são essenciais para o desenvolvimento, não só econômico, mas em uma perspectiva mais ampla, que contemple as dimensões social, política e ambiental, bem como os desafios, contradições e dicotomias que se estabelecem nas relações entre Estado e sociedade. Para a compreensão das políticas públicas, é necessário reconhecer algumas conotações que as colocam como um princípio, um plano ou um curso de ação seguido pelo Estado e/ou sociedade.

Uma política pública, de acordo com Meny e Thoenig (1992), pode ser definida como o resultado da atividade de uma autoridade investida de poder público e de legitimidade governamental. É por meio do ato de fazer políticas (ação ou inação) que funciona a estrutura governamental. As políticas públicas, conforme observa Carvalho (2005), têm sido designadas como algum tipo de ação governamental que apresenta reflexos na sociedade ou em partes dela. A política pública pode, também, ser compreendida como um compromisso público que visa dar conta de determinadas ações, em diversas áreas e que garantam os direitos sociais (RAULI, 2007). As políticas públicas, como resultantes da atividade política, geralmente, envolvem mais de uma decisão e requerem diversas ações estrategicamente selecionadas para implementar as decisões tomadas (RUA, 1997). A política pública também pode ser compreendida como uma atividade política, que segundo Muller e Surel (1998), depende da dinâmica da realidade, visto que esta é construída por distintos atores sociais, considerando que há uma conjuntura, correlações de forças e interesses em jogo.

Diante dessas colocações, assume-se, neste trabalho, a visão de Souza (2006), segundo a qual não existe uma única nem melhor definição sobre o que seja política pública, no entanto, as suas principais características podem ser assim sintetizadas: i) permite distinguir entre o que o governo pretende fazer e o que, de fato, faz; ii) envolve vários atores e níveis de decisão, embora seja materializada por meio dos governos e não necessariamente se restringe a participantes formais, já que os informais são também importantes; iii) é abrangente e não se limita a leis e regras; iv) é uma ação intencional, com objetivos a serem alcançados; v) apresenta impactos no curto prazo e longo prazo; vi) envolve processos subsequentes após sua decisão e proposição, ou seja, implica também implementação, execução e avaliação.

O foco analítico da política pública, ainda segundo Souza (2006), está na identificação do tipo de problema que esta visa corrigir, na chegada desse problema à sociedade política e nas instituições que irão modelar a decisão e a sua implementação. Paralelamente a essa breve descrição de conotações,

Página 60 Caderno de Ciências Sociais Aplicadas, Vitória da Conquista/BA, vol. 16, n 27, ano 16, p. 58-85, jan/jun 2019. 
destaca-se que a análise de políticas públicas tem sido permeada por diversos recortes analíticos que comportam diferentes abordagens teóricas e privilegiam marcos distintos, como a racionalidade instrumental, as instituições, as redes, o processo e a participação social.

Do mesmo modo, Heidemann e Salm (2009) salientam que a transformação das políticas em ações e mudanças efetivas depende de teorias e modelos que auxiliem os agentes a pensá-las e operacionalizá-las. Nesse sentido, destacam-se os modelos referenciais apresentados por Dye (2009).

Institucional - trabalha a política como um produto institucional, ou seja, uma política não se transforma em política pública, antes que seja formulada e implementada por alguma instituição governamental que propicia às políticas públicas três características essenciais: i) legitimidade; ii) universalidade; iii) coerção.

Processo - a política pública é concebida como um conjunto de processos políticoadministrativos, dividido em uma série de atividades (identificação de problemas, organização de agenda, formulação, legitimação, implementação e avaliação). O modelo de processo é um enfoque estreito que circunda a tomada de decisão, mas de grande utilidade, visto que a forma como as políticas são desenvolvidas e implementadas podem ou não mudar o seu conteúdo, devido às restrições sociais, econômicas, tecnológicas, ambientais.

Grupo - concebe a interação entre grupos como o fato mais importante da política. Dessa forma, define como um "grupo de interesse", indivíduos com atitudes compartilhadas que fazem reivindicações a outros grupos da sociedade e que se tornam políticos quando apresentam uma reivindicação por intermédio de qualquer instituição governamental. O grupo torna-se, então, a ponte essencial entre indivíduo e governo, enquanto a política representa as lutas entre os grupos para influenciar as políticas públicas.

Elite - a política pública é vista como resultado das preferências e valores da elite governante, ou seja, flui de "cima para baixo", das elites para as massas (não se originam nas demandas da sociedade). A teoria elitista sugere que a sociedade é apática e mal informada a respeito das políticas públicas e que a elite molda, na verdade, a opinião das massas sobre as questões políticas mais do que as massas formam a opinião da elite. Assim, as políticas públicas traduzem as preferências das elites, enquanto os funcionários apenas executam as políticas estabelecidas pela sociedade.

Racional - a política é pautada por duas importantes orientações que levem a um "ganho social máximo”, ou seja, não se devem adotar políticas cujos custos excedam seus benefícios e os tomadores de decisão devem selecionar, entre as opções, aquela que produza o maior benefício em relação a seus

Página 61 Caderno de Ciências Sociais Aplicadas, Vitória da Conquista/BA, vol. 16, n 27, ano 16, p. 58-85, jan/jun 2019. 
custos. Dessa forma, o racionalismo envolve o cálculo de todos os valores sociais, políticos e econômicos sacrificados ou alcançados por uma política.

Incremental - a política é vista como variações sobre passado, mais especificamente, como uma continuação de governos anteriores com apenas algumas modificações incrementais. Vale destacar que o modelo incremental reconhece a natureza não prática da formulação "absolutamente racional” de políticas e descreve um processo mais conservador de formulação de decisões. O conservadorismo pode ser compreendido no sentido de que os atuais programas, políticas e despesas são considerados legítimos e atenção deve ser concentrada sobre acréscimos, decréscimos ou modificações nos programas e políticas.

Teoria dos jogos - a política pública é concebida como uma escolha racional para situações competitivas e interdependentes. A teoria dos jogos pode ser aplicada em situações de formulação de políticas em que não existe uma escolha a fazer que seja independentemente "melhor" que outras - em que os melhores resultados dependem daquilo que os outros façam. Por ser um modelo abstrato e dedutivo, a teoria dos jogos não descreve como as pessoas de fato tomam decisão, mas como procederiam para tomar decisões em situações competitivas se elas fossem inteiramente racionais.

Opção pública - a política é definida como a deliberação coletiva de indivíduos movidos pelo autointeresse. A teoria da opção pública parte da premissa de que todos os atores políticos - eleitores, contribuintes, candidatos, legisladores, burocratas, grupos de interesse, partidos, burocracias e governos - procuram tornar máximos seus benefícios pessoais, tanto no reino da política quanto no ambiente do mercado. Logo, esses atores se associarão politicamente no intuito de proporcionar benefícios mútuos.

Sistêmica - a política pública é vista como produto do sistema político. O conceito de sistema implica um conjunto identificável de instituições e atividades na sociedade que funcionam no sentido de transformar demandas em decisões oficiais, com apoio indispensável de toda a sociedade. A noção de sistema implica também que elementos do sistema são inter-relacionados: os inputs são recebidos no sistema político tanto sob formas de demandas como apoio, enquanto os outputs (política pública) podem exercer um efeito modificador sobre o ambiente e suas demandas, podendo ter influência sobre o sistema político.

Entre esses modelos conceituais, optou-se, neste trabalho, por contextualizar o modelo processual, ou seja, o ciclo da política pública (policy cycle). Conforme expõe Raeder (2014), o modelo processual propõe um entendimento de que a política pública seja composta por estágios que possuem características específicas e há diferentes formas de conceber os estágios do ciclo que, segundo Secchi

Página 62 Caderno de Ciências Sociais Aplicadas, Vitória da Conquista/BA, vol. 16, n 27, ano 16, p. 58-85, jan/jun 2019. 
(2014), integram um esquema de visualização e interpretação que organiza a vida de uma política em fases sequenciais e interdependentes.

De acordo com Frey (2000), o modelo processual caracteriza-se como uma categoria de relevância e que pode ser dividido em fases parciais do processo político-administrativo: formulação, implementação e avaliação ou controle dos impactos das políticas. Ao subdividir o agir público em fases parciais do processo político-administrativo de resolução de problemas, o policy cycle revela-se um modelo heurístico bastante interessante para a análise da vida de uma política pública. Suas fases correspondem a uma sequência de elementos do processo político-administrativo e que podem ser investigadas no que diz respeito às constelações de poder, às redes políticas e sociais e às práticas político-administrativas típicas de cada fase (MEDEIROS; BORGES, 2007). Portanto, não se trata aqui de apenas descrever as fases que conformam o ciclo como um quadro referencial para a análise de política pública sob a ótica processual, administrativa e racional, mas sim apresentar aspectos de diferentes naturezas que permeiam de forma clara ou oculta a análise de políticas públicas sob a ótica processual. Nesse sentido, o ciclo será compreendido como uma construção política e social que corrobora a ideia de que as políticas públicas não seguem um processo linear e contínuo, pelo contrário, é um processo interativo movido pela dinâmica das relações entre Estado e sociedade, no qual as fases podem se apresentar de forma misturada e com sequências alternadas.

Seguindo os estágios do ciclo da política pública, a formulação deve ser concebida como um processo de planejamento que passa, inicialmente, por um diagnóstico, que deve identificar as reais necessidades das partes envolvidas e estudar quais são as melhores soluções para sua efetivação (AZEVEDO, 2003). O diagnóstico, de acordo com Silva Neto e Serra (2007), pode ser dividido em duas fases: a primeira, que necessita de análises, estudos dos pontos e fatos existentes acerca dos problemas que se quer solucionar com uma política e a segunda, em que devem ser avaliados os aspectos sociais, econômico-financeiros, políticos e jurídicos para encontrar as melhores diretrizes para a solução do problema.

Essa fase da formulação deve, também, ser precedida pela definição de uma agenda que, segundo Calmon e Costa (2007), consiste no processo pelo qual as demandas de vários grupos da população são transformadas em itens aos quais os agentes públicos devem prestar atenção. De acordo com Souza (2006), os governos podem definir a agenda de três formas: i)focalização nos problemas, isto é, problemas entram na agenda quando se assume o que deve ser feito para solucioná-los; ii) focalização na política propriamente dita - constrói-se uma consciência coletiva sobre a necessidade de

Página 63 Caderno de Ciências Sociais Aplicadas, Vitória da Conquista/BA, vol. 16, n 27, ano 16, p. 58-85, jan/jun 2019. 
se enfrentar um dado problema. Essa construção pode ser via processo eleitoral, via mudanças nos partidos que governam ou via mudanças nas ideologias, aliados à força ou à fraqueza dos grupos de interesse; iii) focalização nos participantes, os quais compreendem políticos, mídia, partidos, grupos de pressão, acadêmicos, burocratas, entre outros. Acredita-se que uma agenda com foco nos participantes contemple os outros dois, pois, tanto a solução de um problema quanto a formação de uma consciência política necessitam do estabelecimento e da manutenção de relações de cooperação e colaboração entre os diferentes atores sociais. Sob essa perspectiva, Calmon e Costa (2006) ainda ponderam que, ao focalizar no papel dos atores na formação da agenda, devem-se considerar as diferenças de recursos disponíveis e interesses envolvidos, que podem atrair ou afastar participantes de um determinado debate, alterando, assim, a possibilidade de elaboração de uma política pública.

Dessa forma, o planejamento não pode ser visto como um processo "de cima para baixo" (topdown), ou seja, em que as decisões são tomadas por autoridades que têm certo controle do processo e que decidem o que e como serão formuladas e implementadas as políticas. Pelo contrário, conforme propõe Oliveira (2006), devem-se levar em consideração no fluxo do processo de planejamento aqueles que estão mais próximos das ações resultantes das políticas, ou seja, ver o processo de "baixo para cima”. A população afetada pela política e os agentes do Estado em contato com ela (chamados streetlevel bureaucrats, ou burocratas da rua) devem influenciar de forma mais intensa o processo de planejamento de políticas públicas. O mesmo autor ainda relata que essa concepção se justifica, pois, além de apoiar questões de efetividade e eficiência - pois esses agentes sociais sabem exatamente o que acontece e o que seria melhor para alcançar os resultados da política -, torna-se um processo mais democrático com a participação das partes interessadas nas decisões que lhes afetam.

Nesse sentido, Teodósio (2009) destaca que os atores do Estado e da sociedade têm sido levados a repensar e a reordenar os seus papéis em prol da construção mais avançada e democrática das políticas públicas. Essas formas de colaboração recebem diferentes denominações, seja nos estudos acadêmicos, seja nas iniciativas de intervenção social, configurando uma verdadeira polissemia, na qual se inscrevem variadas formas de articulação colaborativa, como conselhos gestores, orçamento participativo, planejamento participativo e fóruns temáticos, entre outras. Além disso, implicam maior aproximação da sociedade civil com o Estado mediante lógicas menos verticalizadas de relacionamento, o que coloca a descentralização, a participação e o engajamento dos cidadãos como elementos centrais na gestão das políticas públicas.

Página 64 Caderno de Ciências Sociais Aplicadas, Vitória da Conquista/BA, vol. 16, n 27, ano 16, p. 58-85, jan/jun 2019. 
Com relação à segunda fase do ciclo, a implementação, Kelma (2006) caracteriza-a como a fase em que a política pública se materializa, ou seja, é um processo de execução das políticas resultantes da formulação e decisão. Conforme relatam Thompson Jr. e Strickland (2000), a implementação é, principalmente, uma atividade orientada para as operações, que gira em torno do gerenciamento das pessoas e dos processos. A implementação como um meio de execução, segundo Oliveira (2006), trata a forma de como as políticas mudam e passam de diretivas administrativas para a prática, com uma declaração governamental de suas preferências, que são mediadas por um número de atores sociais que criam um processo circular caracterizado por relações recíprocas de poder e negociação. Oliveira (2006) destaca, ainda, que essa segunda fase do processo requer um entendimento de sua complexidade e de sua interação com o processo de planejamento, ou seja, o resultado de um processo de planejamento, incluindo sua implementação, tem que ser visto como uma série de eventos aparentemente simples, mas que dependem de uma cadeia complexa de interações recíprocas para que obtenham o resultado esperado, e muitas vezes essa cadeia não pode ser prevista ou controlada, devido à existência de elementos de diversas naturezas, conforme pode ser observado ao longo da discussão. A participação do cidadão também deve contribuir para a implementação das políticas públicas por meio da institucionalização de uma gestão social que possibilita a cogestão e a participação dos cidadãos nas decisões públicas (TENÓRIO; SARAVIA, 2007). Tal gestão deve ser permeada por uma ação política deliberativa, na qual o indivíduo participa decidindo seu destino como pessoa, eleitor, trabalhador ou consumidor: sua autodeterminação ocorre pela lógica da democracia e não pela lógica do mercado (PAES DE PAULA, 2005).

Observa-se que os meandros da construção de políticas públicas são bastante complexos, visto que o desenho de tais políticas deve levar em conta as necessidades das populações que se pretende atender, atentando para a disponibilidade de recursos e outras restrições de diversas naturezas. Nesse sentido, Mafra e Naves (2009) ponderam que, se na elaboração das políticas públicas e na definição de prioridades e conteúdos há muitas dificuldades, o processo de implementação envolve igualmente muitos conflitos, que podem se distanciar de sua proposição original ou, mesmo, inviabilizar sua execução. Por isso, todas as decisões que percorrem o processo de implementação devem ser consideradas passos essenciais. Nesse contexto, Rua (1997) orienta que a mera formulação de uma política e a consequente elaboração de um plano não garantem a viabilidade de sua implementação. Segundo essa autora, existem algumas pré-condições necessárias para que uma política pública tenha uma boa implementação, tais como: i) o programa deve dispor de tempo e recursos suficientes; ii) em

Página 65 Caderno de Ciências Sociais Aplicadas, Vitória da Conquista/BA, vol. 16, n 27, ano 16, p. 58-85, jan/jun 2019. 
cada estágio da implementação deve haver a combinação de recursos necessária para cumprir seus objetivos; iii) deve haver completa compreensão quanto aos objetivos a serem atingidos; iv) é necessário que haja perfeita comunicação entre os vários elementos envolvidos no programa.

Além disso, Silva Neto e Serra (2007) consideram que a falta de visão sobre os potenciais problemas que podem surgir durante a execução de uma política, inevitavelmente, resulta em paralisações, descontinuidades de ações e prejuízos. As vicissitudes e os obstáculos que ocorrerem na fase de implementação estão associados, segundo Martes et al. (1999), a problemas de ordem variada, tais como a capacidade institucional dos agentes implementadores e as disputas políticas. Com relação aos agentes implementadores de política pública, Lotta (2008) destaca a importância dos burocratas ou agentes de rua, que são funcionários que trabalham diretamente no contato com os usuários dos serviços públicos, como, por exemplo, policiais, professores, profissionais de saúde e técnicos. Conforme relata essa autora, pelo fato de esses agentes serem elos que determinam o acesso do público a direitos e benefícios governamentais, consequentemente, é também, na maioria das vezes, por meio deles que a população consegue acessar as políticas públicas, à medida que eles interagem continuamente com a população em seu trabalho. Tais agentes, por fazerem parte de uma estrutura institucional, têm o poder de implementar as políticas públicas, nas quais podem exercer o que Lipsky (1980), citado por Lotta (2008), denomina discricionariedade. A discricionariedade desses agentes está em determinar a natureza, a quantidade e a qualidade dos benefícios e as sanções fornecidas por sua agência. Mesmo que as dimensões políticas oficiais moldem alguns padrões de decisão, bem como as normas comunitárias e administrativas, esses agentes ainda conseguem ter autonomia para decidir como aplicá-las e inseri-las nas práticas da implementação. É, em parte, no exercício da discricionariedade dos agentes implementadores que as políticas públicas são alteradas e reconstruídas. As disputas políticas, segundo Lotta (2008), são oriundas da diversidade de agências, instituições e pessoas envolvidas no processo de implementação e, portanto, são muitas as pressões, valores, princípios e objetivos que entram em jogo nas decisões. Essas estruturas canalizam relações pessoais e institucionais que influenciam a formação de preferências e constrangem escolhas, estratégias e alianças.

Já a terceira fase, a avaliação, é concebida por Azevedo (2003) como o exame sistemático e objetivo das políticas públicas com vistas a observar a efetividade e a relevância da ação social na realidade em que foi implementada. De acordo com Carvalho (2005), a avaliação e o monitoramento podem ser utilizados para a correção de rumos de como a política tem sido praticada, ou seja, abrangem um estudo em que o antes e o depois devem ser comparados e analisados seguindo parâmetros

Página 66 Caderno de Ciências Sociais Aplicadas, Vitória da Conquista/BA, vol. 16, n 27, ano 16, p. 58-85, jan/jun 2019. 
estipulados pelos gestores. Com relação ao momento em que deve ser realizada a avaliação, Assumpção e Campos (2009) caracterizam três: antes (ex-ante) do início, durante (in-itineri) e depois (ex-post) da política pública executada. Na primeira, a avaliação ex-ante, a agenda política e institucional permite escolher as melhores estratégias para a consecução dos objetivos da política. Nesse momento, as avaliações têm papel formativo e conceitual, pois, preferências, formulação e pesquisa de opinião irão identificar as necessidades e o planejamento para a implementação da política. No momento in-itineri busca-se avaliar e monitorar a política em curso. No ex-post, o papel é somativo e avalia-se a política já realizada para estabelecer decisões de continuidade e alterações, bem como estabelecer o impacto da ação. Dessa forma, a avaliação de políticas públicas permite que os formuladores e os implementadores sejam capazes de, objetivamente, tomar decisões com maior qualidade, maximizando o gasto público nas diversas atividades de intervenção estatal, identificando e superando pontos de estrangulamentos e êxitos das políticas e, por consequência, abrindo perspectivas mais racionais para implementar e formular políticas públicas. Por outro lado, Assumpção e Campos (2009) ressaltam que a avaliação de políticas públicas é amplamente debatida e pouco aplicada em sua essência. Quando aplicada, limita-se a controlar investimentos financeiros realizados ou simplesmente servir como relatório das atividades desenvolvidas, não refletindo em efetividade para atribuir valor ou mérito da ação social. Do mesmo modo, Faria (2003) reforça que há uma prevalência nas avaliações de um viés francamente normativo e/ou uma priorização dos aspectos mais técnicos. Nesse sentido, esses autores propõem que a avaliação não contemple apenas aspectos considerados importantes sob a lógica da objetividade economia, eficiência e eficácia - mas, sobretudo, aspectos como a equidade, a participação e o "empoderamento", que tornam o exercício da avaliação mais desafiador.

Ressalta-se que, sob a lógica processual, essas três fases do ciclo das políticas públicas elucidam a noção de estratégia como instrumento de tomada de decisão e alcance de metas (AZEVEDO, 2003). Essa configuração estratégica das políticas públicas, entretanto, pode apresentar falhas que, segundo Rocha e Cerqueira (2003), são formadas pela interferência de elementos de diversas naturezas que vão desde a proposição até a definição e a operacionalização das políticas públicas. Portanto, conforme adverte Azevedo (2003), a ineficácia das políticas públicas está basicamente: i) na ausência de uma visão estratégica, que decorre na inadequação do foco definido; ii) no fracasso quanto à identificação dos obstáculos para que os grupos beneficiários tenham acesso efetivo aos programas e iii) na fragmentação das ações, derivando em desperdícios de recursos e a atuação nas consequências. Martins (2004)

Página 67 Caderno de Ciências Sociais Aplicadas, Vitória da Conquista/BA, vol. 16, n 27, ano 16, p. 58-85, jan/jun 2019. 
também confirma esse último aspecto ao caracterizar a fragmentação como o resultado de um processo descoordenado, inconsistente e incoerente da formulação e implementação de política.

A fragmentação, segundo esse autor, pode ser atribuída à falta de coerência, consistência e coordenação presentes nas políticas públicas. Por conseguinte, para que haja coerência entre políticas públicas, Martins (2004) destaca que elas devem se apoiar mutuamente, não sendo contraditórias. No entanto, a coordenação nas políticas significa fazer com que os diversos sistemas institucionais que formulam políticas trabalhem juntos de forma congruente. Deve-se salientar, ainda, que uma política aplicada de modo conjunto, sob a forma de parcerias, pode significar a interação de toda a sociedade em prol dessa ação. Abre-se, portanto, espaço para uma nova concepção de políticas públicas - a gestão integrada ou em rede, na qual ocorre a substituição de um ator único por um composto que, conforme Peci (2000), se caracteriza por possuir múltiplas organizações geradoras de decisões e ações. Por outro lado, Gaetani (2008) ressalta a possibilidade de dois problemas-chave dificultarem a coordenação de uma rede de política pública, isto é, a necessidade de fazer com que as pessoas de diferentes instituições trabalhem de forma articulada, como também, a necessidade de promover o contínuo alinhamento de incentivos, culturas e estruturas, de modo a se produzir uma integração maior das instituições. Com relação à consistência nas políticas, Martins (2004) salienta que essa deve assegurar que as políticas individuais não sejam internamente contraditórias e que as políticas que se opõem ao alcance de um determinado objetivo sejam evitadas. Agregam-se, ainda, à fragmentação das políticas públicas, os seguintes fatores apresentados por Martins (2004) e Tenório e Rosenberg (2000): a complexidade característica de um macrocontexto de democracia e globalização, promovendo incerteza, pluralidade e ambiguidade; a natureza das políticas públicas; as falhas estruturais, decorrentes de problemas de cooperação; a sedimentação de posições de poder que poderiam se beneficiar de uma coordenação ineficiente, tornando-se uma perversa inteligência por trás dos arranjos de coordenação; o descrédito com relação às instituições públicas e a descontinuidade administrativa e a carência de recursos, sobretudo os de natureza financeira e a falta de apoio da sociedade.

A fragmentação como uma condição crítica que aflige em alguma extensão sociedades, governos e organizações, também pode ser justificada pela ênfase dada ao tecnicismo, burocracia e controle utilizado na formulação e implementação de políticas públicas. Segundo Oliveira (2006), o viés tecnocrata e burocrático que permeia a fase de planejamento das políticas públicas, geralmente, concebe o plano como algo certo, cuja implementação ocorre de forma automática. Porém, a realidade tem mostrado experiências fracassadas de planejamento, com planos discrepantes que no papel funcionam,

Página 68 Caderno de Ciências Sociais Aplicadas, Vitória da Conquista/BA, vol. 16, n 27, ano 16, p. 58-85, jan/jun 2019. 
mas, na prática, alcançam resultados decepcionantes ou desastrosos. Além disso, a ênfase dada à burocracia na formulação e no controle tende a colocar sombra na parte mais importante das políticas públicas - o processo de decisão - que, segundo Oliveira (2006), deve ser compreendido como uma construção política e social. Portanto, o processo de construção de políticas públicas não pode ser controlado apenas de cima para baixo pelos tecnocratas, sem levar em consideração aqueles que são os beneficiários ou que estão mais próximos das ações resultantes das políticas. É necessário que haja uma descentralização para que outras partes interessadas participem desse processo. Nesse sentido, acrescentam-se as considerações feitas por Medeiros e Borges (2007) sobre a participação cidadã como instrumento fundamental na análise de políticas públicas. Para esses autores, o objetivo da participação consiste em possibilitar o contato mais direto entre os cidadãos e as instituições públicas, para que estas considerem os interesses e as concepções político-sociais dos primeiros no processo decisório. Estabelece-se, assim, uma forma de intervenção dos atores sociais na vida pública, visto que a participação é um mecanismo de redistribuição do poder que permite aos cidadãos excluídos dos processos políticos e econômicos a oportunidade de deliberar sobre o futuro da sociedade, reduzindose, assim, as lacunas tão presentes nas relações Estado-sociedade.

Vale ressaltar, do mesmo modo, a importância da dimensão institucional para uma compreensão reflexiva do ciclo da política pública. Não se pode desconsiderar, nessa análise, que os atores, com interesses e recursos distintos, envolvem-se em interações diferenciadas, com pautas de jogo provavelmente distintas em cada política, gerando redes de interações que podem resultar na incorporação de instituições como marco para o processo de elaboração e implementação das políticas públicas. Por constituírem elementos essenciais para a compreensão da ação individual, tendo vida própria, definindo interesses, crenças e ideias, as instituições redefinem regras, normas e estruturas que podem influenciar as alternativas políticas (VICENTE, 2009; SOUZA, 2006). Nesse sentido, Pires (2002) destaca que a política pública é também um produto de um contexto constituído com base em fatores estruturais e institucionais. Portanto, a análise de políticas públicas carece de enfoques que ampliem o olhar para a cadeia de agentes envolvidos nos processos, considerando que esses estão em contínua interação. É preciso analisá-las de forma que se perceba a complexidade na dinâmica da sua formulação e sua operacionalização, ou seja, desde o surgimento da ideia, a elaboração até o amadurecimento da mesma e a sua efetivação, resultando em uma ação pública (VIEIRA, 2010). Devese ir além de avaliar seus resultados em relação ao atendimento aos direitos sociais, visto que as políticas

Página 69 Caderno de Ciências Sociais Aplicadas, Vitória da Conquista/BA, vol. 16, n 27, ano 16, p. 58-85, jan/jun 2019. 
públicas envolvem, também, a organização da sociedade civil, os interesses de classes, os partidos políticos e os agentes responsáveis pela sua elaboração, operacionalização e controle.

Acredita-se que essas sejam algumas das orientações que permeiam a análise de políticas públicas sob a perspectiva de um ciclo que não deve ser concebido de forma simples e linear, nem pode, por definição, possuir um ponto de partida claramente definido. Para que ele possa ser mais bem representado, conforme relatam Martes et al. (1999), deve-se considerá-lo um complexo fluxo de ações e decisões de governo, um conjunto de atores sociais que dão sustentação à política e, finalmente, por "nós" ou "elos" críticos que representam a capacidade de coordenação interinstitucional. As fases do ciclo de política pública com frequência não se fecham em um processo circular, mas acontecem de maneira não linear, por vezes, concomitantes, e sem uma clara e pré-determinada sequência temporal, em um complexo processo no qual os atores e instituições interagem entre si e podem participar mais de uma fase (OLIVEIRA, 2013).

Reconhecendo o modo didático e metodológico de analisar as políticas públicas sob a ótica de um ciclo não linear e com seus estágios de formulação, implementação e avaliação, torna-se necessário reforçar duas categorias dicotômicas que foram sucintamente aqui debatidas. Trata-se do "Estado e sociedade", do "saber técnico e saber local".

\section{Contexto das relações entre Estado e sociedade}

Apreender o ciclo da política pública sob uma perspectiva reflexiva requer uma referência ao contexto das inter-relações entre Estado e sociedade. Iniciando pelo papel do Estado, Souza (2006) destaca a importância de se debater o espaço que cabe a esse ator para definir, implementar e avaliar políticas públicas, considerando que esse tem um escopo próprio de atuação, permeado por influências externas e internas. Reconhecendo que o conceito de Estado é muito amplo, acredita-se que os paradigmas de gestão pública, como um dos focos de explicação, possam esclarecer algumas implicações para a análise de política pública. A gestão pública é permeada por contextos político, econômico e social que impõem transformações macroinstitucionais e que afetam o papel do Estado na gestão dessas políticas.

Com fundamento nessa concepção de que os paradigmas de gestão pública compreendem macro-orientações que moldam projetos políticos e aparelhos de Estado (OLIVEIRA et al., 2008), torna-se necessário, ainda que de forma breve, apresentá-los, quais sejam: patrimonial, burocrática, gerencial e societal.

Página 70 Caderno de Ciências Sociais Aplicadas, Vitória da Conquista/BA, vol. 16, n 27, ano 16, p. 58-85, jan/jun 2019. 
Considerando a longa tradição autoritária das formas de gerir o Estado, desde o período colonial no Brasil, o patrimonialismo pode ser entendido como uma forma de dominação tradicional (FAORO, 2000) representada pela vontade do dominador e legitimada pela obediência dos dominados, que não se constituem uma sociedade civil contraposta ao Estado. Como uma orientação para a administração pública, as decisões são permeadas pelo poder pessoal e arbitrário do soberano e de seus representantes (OLIVEIRA et al., 2008), o que, consequentemente, reflete na gestão das políticas públicas, sendo marcantes os traços como o clientelismo, o personalismo e o assistencialismo.

Entre as formas de romper com o patrimonialismo, a orientação burocrática desponta como uma das alternativas devido à sua superioridade técnica, racional e legal para delimitar regras e instituições para a administração do setor público. Nesse sentido, Torres (2007) destaca que o modelo burocrático desempenhou papel fundamental, criando condições que possibilitaram a expansão quantitativa e qualitativa da administração pública. Com relação às principais características do modelo burocrático, esse autor enfatiza: a impessoalidade; a hierarquia; a elaboração de regras rígidas; a especialização; a continuidade e o controle. Por outro lado, há um questionamento sobre a legitimidade da burocracia como uma orientação para a administração pública, devido às suas disfunções. De acordo com Saraiva e Capelão (2000), inúmeros desajustes são causados pela burocracia, principalmente aqueles que se referem à prestação de serviços públicos, sendo essa referenciada como lenta, cara, de péssima qualidade e pouco ou nada orientada para o atendimento das demandas dos cidadãos. Portanto, a imagem da administração pública burocrática passa a ser associada à ideia de precariedade, pois, em determinados setores, ela está alicerçada por um conjunto de ineficácia, morosidade, empreguismo, obsoletismo, desmotivação de quadros, inércia, inadequação de funções e serviços desqualificados. Vale destacar que tanto as características quanto as vicissitudes da burocracia afetam a gestão de políticas públicas, merecendo destaque a especialização, que difundiu a ideia de que as políticas públicas são produtos estritamente tecnicistas, sendo, portanto, dominadas pelos burocratas.

Enquanto a orientação burocrática prioriza uma rigidez processual no setor público, o setor privado focaliza em processos de inovação e flexibilidade que, posteriormente, passaram a ser visualizados como uma alternativa para desmantelar as disfunções da burocracia. Esse ataque à burocracia foi um dos pontos de partida para a introdução no setor público de ideias, valores e técnicas gerenciais do setor privado, denominado movimento da Administração Pública Gerencial ou Nova Administração Pública (BRESSER PEREIRA, 2000). A possibilidade de instalar, no setor público, processos gerenciais e instrumentais do setor privado pauta-se, conforme relata Fadul e Silva (2008), na

Página 71 Caderno de Ciências Sociais Aplicadas, Vitória da Conquista/BA, vol. 16, n 27, ano 16, p. 58-85, jan/jun 2019. 
capacidade de adotar uma gestão pública de eficiência, eficácia, racionalidade e produtividade. Entre as premissas para administração pública gerencial destacam-se: a privatização de empresas estatais; a concessão e a terceirização de serviços públicos, seguindo a lógica do downsiz̨ing e descentralização; a busca pela excelência e a adoção de princípios de qualidade; a transparência e a avaliação de resultados; o foco nos resultados; adoção de práticas de accountability; foco no cidadão-consumidor e a capacitação dos recursos humanos, entre outras. Aliado a essas premissas, Bresser Pereira e Grau (1999) ressaltam que esse tipo de administração representa uma forma estratégica moderna de o Estado separar as atividades que lhe são exclusivas, as não exclusivas e a produção de bens e serviços para o mercado. $\mathrm{O}$ modelo de administração gerencial, de acordo com os mesmos autores, não representa uma forma oposta ao mercado e nem ao Estado, entretanto, valoriza o uso de outro setor para que se elevem os interesses públicos. Dessa forma, eles sugerem o setor público não estatal como um campo privilegiado para gerir essas atividades, sendo representado por um conjunto de organizações sociais que, por um lado, sendo privadas, não visam fins lucrativos, e, por outro, são consideradas públicas porque estão voltadas para o interesse público e não estatais porque não fazem parte do aparato do Estado. Além disso, essas organizações representam um espaço para a democracia participativa ou direta, proporcionando a participação cidadã nos assuntos públicos e no controle social. Entre tais organizações destacam-se as cooperativas, as associações, as organizações não governamentais, as organizações de voluntariado e as organizações comunitárias ou de base.

Com relação à gestão de políticas públicas sob a orientação gerencial, observam-se alguns avanços que recaem, principalmente, sobre o papel do setor público não estatal como um espaço para a democratização do processo decisório das políticas públicas. Do mesmo modo, observa-se uma preocupação da administração pública gerencial em adotar a descentralização que, no âmbito das políticas públicas, pode ser caracterizada como um processo de reestruturação interna ao aparelho do Estado, no intuito de proporcionar mais poder àqueles que estão perto dos cidadãos e de suas necessidades (MAFRA; NAVES, 2009). Essa transferência de poder do nível nacional para instâncias subnacionais permite planejar, gerir, executar e tomar decisões de forma mais eficiente. Nesse sentido, espera-se que uma política descentralizada articule as iniciativas da sociedade civil, contribua para a sua publicização e crie condições para que possa ser exercida a fiscalização sobre as decisões tomadas e o uso dos recursos públicos (ROCHA; PAULA, 2005).

Por outro lado, a provisão de políticas públicas sob a orientação gerencial apresenta, segundo autores como Oliveira et al. (2008) e Teodósio (2009), uma natureza dúbia e contraditória quanto à 
construção e ao fortalecimento de instituições mais abertas à participação social pelo poder público, visto que este tende a priorizar as dimensões estruturais para a adoção de uma gestão nos moldes empresariais em detrimento de formas mais efetivas de diálogo e interação com a sociedade civil na produção de políticas públicas. Além disso, observam-se alguns recuos no processo de descentralização, visto que é comum a ocorrência da descentralização apenas na execução das políticas públicas, mantendo centralizado todo processo decisório. A descentralização não pode ocorrer de forma dissociada do processo político, pelo contrário, deve-se somar a capacidade de influir e orientar as políticas públicas para as necessidades da sociedade.

Diante disso, observa-se que a administração pública gerencial não atende aos anseios para a democratização do Estado, o que leva, segundo Oliveira (2009), a refletir sobre uma nova forma de gestão pública. Nesse sentido, insere-se a orientação societal que tem como foco a dimensão sóciopolítica da gestão e que tenta resgatar as relações entre o Estado e a sociedade sob a perspectiva dos direitos de cidadania e de participação (PAES DE PAULA, 2005). Portanto, trata-se de estabelecer uma gestão pública que não centraliza o processo decisório no aparelho do Estado e contempla a complexidade das relações políticas, pois procura se alimentar de diferentes canais de participação, além de modelar novos desenhos institucionais para conectar as esferas municipal, estadual e federal. Essa orientação deve ser permeada por um projeto político que procure ampliar a participação dos atores sociais na definição da agenda política, criando instrumentos que possibilitem maior controle social sobre as ações estatais e desmonopolizando a formulação e a implementação das ações públicas. Entre os canais de participação destacam-se os fóruns temáticos, os conselhos gestores de políticas públicas e o orçamento participativo. A gestão social, de acordo com Tenório e Saravia (2007), agrega valores democráticos à gestão pública, visto que o processo decisório considera a soberania popular e é voltada ao interesse público. Como uma orientação para a gestão de políticas públicas, a gestão social incorpora a participação da sociedade por meio de um processo deliberativo, dialógico e cogestionário. Dessa forma, essa orientação transcende os limites da descentralização das ações entre os níveis de governo, visto que os cidadãos fazem parte do processo de planejamento e implementação de políticas.

Vale destacar que as duas primeiras orientações - patrimonial e burocrática - possuem um caráter estadocêntrico que, segundo Teodósio (2009), compreende a formulação e a implementação de políticas públicas como função intransferível e central do Estado, excluindo a sociedade civil. Por outro lado, a terceira orientação tem uma visão mercadocêntrica, a qual entende que devem ser transferidas as premissas da gestão empresarial para que as organizações públicas sejam providas de maior eficiência e

Página 73 Caderno de Ciências Sociais Aplicadas, Vitória da Conquista/BA, vol. 16, n 27, ano 16, p. 58-85, jan/jun 2019. 
otimização de recursos. Por fim, a quarta orientação apresenta uma perspectiva sociocêntrica, para a qual o papel do Estado seria reconfigurado com base na dinâmica dos atores da sociedade civil na esfera pública. Essas orientações, de acordo com Filippim e Rossetto (2006), foram construídas socialmente na trajetória política do Brasil, sendo comum, nos dias atuais, a coexistência e a fusão dessas diferentes orientações no modo de ser e de agir da administração pública nacional, estadual e municipal. Portanto, essas orientações não são estanques e circunscritas a um único período de tempo. Pelo contrário, todas essas abordagens se entrecruzam na teoria e na prática da administração pública brasileira.

Reconhecendo a dialética que se instaura no processo político e histórico da administração pública brasileira, reforça-se a necessidade de reconhecer a gestão social amparada pela participação de diversos atores da sociedade civil no processo de elaboração, implementação e avaliação de políticas públicas. A participação deve ser visualizada como um caminho a ser perseguido para que se instaure um desenvolvimento legítimo, ou seja, que vá além dos moldes econômicos, considerando as complexidades e as subjetividades que envolvem a sociedade (SILVA; SILVA, 2009). Do mesmo modo, ela não deve ser compreendida como um conceito neutro e, sim, como interação e ação social, cujo objetivo pode ser a conservação, o aprimoramento ou a transformação da sociedade. Como uma ação social, a participação requer a institucionalização das relações entre o Estado e a sociedade, o que pode estar associado ao processo de revalorização da esfera local, enquanto instância de criação e estímulo à participação. É no âmbito dos governos municipais que diversos mecanismos inovadores de gestão pública, baseados em maior participação social, estão sendo disseminados (CARVALHO, 2005; OLIVEIRA, 2009). A participação cidadã pode gerar um sentimento de pertencimento ao lugar e de "empoderamento" nas pessoas e grupos, que são fatores essenciais para o surgimento de uma consciência de cidadania (GATTAI; ALVES, 2008). De acordo com Pires (2002), a participação cidadã nas políticas públicas tende a intensificar a atividade de planejamento no interior dos governos, visto que a abertura do espaço à participação, consequentemente, instala um fluxo de informações entre a administração pública e o cidadão que impõe ao governo não só a necessidade de estabelecer um diálogo aberto e transparente, como também de organizar informações, metas, planos e prazos. A implementação de políticas públicas por meio de práticas participativas, conforme ressaltam Tenório et al. (2008), deve se fundamentar em esforços articulados de atores estatais e da sociedade, dispostos a levar adiante projetos que surjam da negociação de interesses, inclusive divergentes e em conflito.

Página 74 Caderno de Ciências Sociais Aplicadas, Vitória da Conquista/BA, vol. 16, n 27, ano 16, p. 58-85, jan/jun 2019. 
As práticas participativas não se opõem a democracia representativa. Pelo contrário, buscam aperfeiçoá-la e, também, complementá-la à medida que exigem o controle social, a transparência e a democratização das decisões públicas. Por outro lado, é válido reconhecer as dificuldades para a prática da participação, o que pode ser considerado como resquícios da cultura patrimonialista no Brasil. Além disso, Carlos e Silva (2006) alegam que é comum a sociedade atribuir à participação um sentido que remete ao seu valor instrumental, ou seja, a participação compreendida em sua relação com a obtenção de bens materiais. Também seria conveniente considerar que a participação não está despida das contradições que perpassam a formação da sociedade brasileira, como, por exemplo, a falta de mobilização coletiva e o individualismo. Predomina no Brasil, conforme expõem Gattai e Alves (2007) e Torres (2007), uma sociedade civil fraca e desarticulada, com dificuldades para ocupar o espaço público e lutar pelos seus direitos, o que, consequentemente, atrapalha o exercício de uma democracia participativa, deixando espaço para práticas corruptas e clientelistas. Nesse sentido, esses autores ressaltam a importância da formação de capital social para o exercício da democracia participativa, o que carece de uma mudança cultural da sociedade civil para que esta se organize e lute pelos seus direitos. Essa mudança cultural é possível por meio de processos educativos que contextualizem a participação como uma forma de ação coletiva.

Tenório e Rosenberg (1997) ressaltam que, para que a participação seja considerada legítima, ela deve reunir os seguintes atributos: i) os participantes devem ter consciência sobre os seus atos, ou seja, do processo que estão vivenciando, pois caso contrário, a participação é restrita, visto que alguma espécie de relação de dominação ou de poder persuasivo pode se impor, tornando a participação como um simples adestramento; ii) a participação não deve ser imposta, concedida ou doada porque a sua legitimidade está na sua conquista gradual que ocorre por meio da conscientização da sua importância, da negociação de espaços para o seu exercício e do estabelecimento das regras que irão democraticamente delimitar a sua prática; iii) outro aspecto ratifica que o valor da participação conquistada é o processo de internalização e de absorção desse direito por parte dos beneficiários; iv) a voluntariedade da participação também contribui para a sua legitimidade, pois é contraditório reivindicar a obrigatoriedade para um processo que se deseja consciente e gerador de um indivíduo mais comprometido com mudanças. A participação, portanto, deve ser vista como o conteúdo substantivo que dá acesso à cidadania. Em sua plenitude, a cidadania só se consolida na presença de uma participação entendida como um exercício consciente, voluntário e conquistado.

Página 75 Caderno de Ciências Sociais Aplicadas, Vitória da Conquista/BA, vol. 16, n 27, ano 16, p. 58-85, jan/jun 2019. 
Vale ressaltar que não há aqui a pretensão de esgotar os limites da abrangência dos assuntos aqui abordados, mas destacar que a participação consiste em uma problemática que carece de atenção na discussão sobre desenvolvimento e análise de políticas públicas. Ao permitir um contato mais direto e cotidiano entre os cidadãos e as instituições públicas, a participação possibilita um real diálogo entre os diferentes atores com suas concepções de mundo distintas. Logo, "participar é repensar um saber em confronto com outros saberes" (TENÓRIO, 2007, p.116). É nesse sentido que serão traçadas, a seguir, algumas considerações sobre as contribuições do saber técnico (setor público) e do saber local (sociedade) na análise de políticas públicas.

\section{Saber técnico e saber local}

Considerando que a participação inclui o uso do saber dos atores sociais, torna-se necessário tecer algumas reflexões sobre o saber técnico das instituições do setor público e o saber local da sociedade, propondo a interação do uso desses saberes na análise de políticas.

Com relação ao saber técnico, observa-se que este deriva do saber científico, que segundo Scalabrin et al. (2009) e Rozemberg (2007), pauta na objetividade, determinismo e rigorosidade das ciências naturais. Transpondo para o contexto das instituições do setor público, o saber técnico configura um elemento estratégico para o Estado, formado por um grupo de especialistas que assumem o papel de atores principais nas decisões de Estado em relação à sociedade. Como um paradigma, a tecnocracia pressupõe que as decisões sobre as políticas públicas fiquem subordinadas ao quadro técnico do governo, que toma as decisões com base apenas em padrões racionais, sem levar em consideração as necessidades e as heterogeneidades da sociedade ou os conflitos que são inerentes ao mundo da política (ALCÂNTARA, 2007). O planejamento de políticas públicas sob a perspectiva tecnocrata consiste, basicamente, segundo Oliveira (2006) e Nascimento e Zuquim (2009), na elaboração de planos pelas instituições estatais e que podem ser pautados por critérios técnicos e econômicos, discutidos em reuniões ou apresentados em estudos como, por exemplo, mapas detalhados, modelos matemáticos e cenários, construção de indicadores. Finalizada essa etapa, espera-se que ações planejadas sejam coerentes com o orçamento, para que, assim, possam ser implementadas e alcancem os resultados esperados. Ao separar as etapas de formulação e implementação das políticas públicas pode ocorrer um distanciamento das reais necessidades dos beneficiários, bem como um distanciamento nas relações entre Estado e sociedade. Do mesmo modo, Rocha (2005) observa, em seu trabalho, que, dependendo da autonomia, alguns tecnocratas podem priorizar políticas que atendam às

Página 76 Caderno de Ciências Sociais Aplicadas, Vitória da Conquista/BA, vol. 16, n 27, ano 16, p. 58-85, jan/jun 2019. 
suas ideias, às necessidades de suas carreiras e de suas instituições, em detrimento do interesse comum da sociedade. Outra possibilidade, segundo Storino (2001), caracteriza-se quando um tecnocrata, julgando conhecer a melhor alternativa para os problemas, não reconhece que os atores sociais poderiam identificar outro caminho, por meio de soluções criativas, seguras e, por vezes, menos custosas para uma política pública.

A tecnocracia, portanto, constitui uma projeção da racionalidade instrumental na gestão pública, visto que sua orientação concentra-se no cálculo de meios e fins em detrimento do conteúdo intersubjetivo inerente a qualquer relação social (TENÓRIO, 2003). Complementando essa visão, Souza (2006) destaca que, ao superestimar os aspectos racionais e procedimentais das políticas públicas, o saber técnico ignora a essência da política pública, isto é, o embate em torno de ideias e interesses. Pode ocorrer, então, uma negligência do contexto para o qual uma política pública será criada e aplicada. Fundamentada nesse viés técnico, quantitativo e unilateral, a análise de políticas públicas torna-se, então, limitada, pois não se assume a ideia de que os avanços qualitativos dependem da mediação das relações e dos saberes das diversas instituições do Estado com a sociedade civil em prol de uma gestão de políticas públicas em conjunto.

Diante disso, torna-se relevante incluir o saber dos atores locais que serão os beneficiários das políticas públicas, bem como as suas experiências, estilos de vida, percepções e valores, entre outros. Com relação aos atores locais, Tenório et al. (2008) destacam que estes são representados por todos os agentes que, no campo político, econômico, social e cultural são portadores e fomentadores das potencialidades locais. Um olhar para o saber local implica, então, reconhecer que o contexto, as tradições e os valores influenciam na compreensão da realidade social dos atores, podendo esta ser utilizada para identificar os problemas, as necessidades e as aspirações que permeiam uma política pública.

A inclusão do saber local no processo de políticas públicas muda a cultura predominante de desenvolvimento, que deixa de ser uma coisa que se espera pacientemente, ou seja, que é promovido de uma perspectiva de "cima para baixo", e torna-se uma coisa que se faz, gera-se o sentimento de apropriação e domínio da sua própria realidade (DOWBOR, 2010). O saber local gera subsídios para a formulação de políticas públicas relacionadas à realidade e que consequentemente solucionam os problemas bem como promovem o desenvolvimento, tornando assim o processo de políticas públicas reconhecido e legitimado pelos atores sociais (FERNANDES; SAMPAIO, 2006).

Página 77 Caderno de Ciências Sociais Aplicadas, Vitória da Conquista/BA, vol. 16, n 27, ano 16, p. 58-85, jan/jun 2019. 
Nesse sentido, Beduschi Filho e Abramovay (2004) reforçam que o saber local consiste no locus primário para a elaboração de uma política pública, pois é fruto das razões, particularidades e das experiências vividas dos sujeitos sociais. Além disso, sob a perspectiva do saber local, os atores deixam de ser meros objetos e receptores das políticas e passam a ser também agentes dos processos de transformação social. Para incluir o saber local na análise de políticas públicas, torna-se necessária a criação de canais deliberativos, nos quais os atores possam expressar suas posições, confrontá-las e negociá-las. Esses canais já têm sido trabalhados pela gestão social, tais como os fóruns temáticos, os conselhos gestores de políticas públicas e o orçamento participativo. Esse saber local pode ser, também, denominado um conhecimento prático, empírico ou até de senso comum, caracterizado por Santos (1988) como uma das mais importantes formas de conhecimento, que orienta as ações e dá sentido à vida. $\mathrm{O}$ mesmo autor ainda acrescenta que o conhecimento do senso comum tende a ser um conhecimento mistificado e mistificador, mas que, apesar disso, pode ter uma dimensão libertadora e emancipatória que, segundo Naves (2005), representa, para os atores, uma passagem de uma condição de passividade para uma condição de agentes que vivem na interdependência direta e indireta com a natureza nos locais onde se pretende intervir e que dispõem de conhecimentos e experiências que podem constituir um saber essencial para pensar o que é essa realidade.

Considerar o saber local no processo de políticas não só pode melhorar a qualidade da tomada de decisão, levando a uma melhor política, mas também, pode aumentar a probabilidade de que a implementação da política seja mais legítima, eficaz, eficiente e sustentável. Uma maior participação e o reconhecimento das particularidades do local eleva a confiança do público no processo de tomada de decisão, proporcionando um foco para a construção de perspectivas comuns, soluções acordadas e interações para realizar os objetivos desejados comumente (SAWHNEY, et al, 2007).

Por outro lado, não se pode desconsiderar a importância do saber técnico, principalmente, o seu engajamento para a realização de pesquisas que muito fomentam com informações, indicadores e modelos quantitativos da gestão de políticas públicas. O que se observa, nas discussões de autores como Rozemberg (2007), Tenório (2008), Deponti (2009) e Scalabrin et al. (2009), é que o saber puramente técnico pode não compreender todos os meandros que conformam a realidade social que permeia a formulação, a implementação e a avaliação de uma política pública. Para superar a ortodoxia do saber técnico, deve-se partir da perspectiva de que não há verdades técnicas absolutas, pois todo saber técnico é provisório e dependente do contexto histórico, no qual os fenômenos são observados e interpretados. Por isso, o saber dos atores locais é importante quando articulado ao saber técnico e

Página 78 Caderno de Ciências Sociais Aplicadas, Vitória da Conquista/BA, vol. 16, n 27, ano 16, p. 58-85, jan/jun 2019. 
vice-versa (SCALABRIN et al. 2009). Acredita-se que a socialização desses dois tipos de saberes (técnico e local) colabora com a construção de políticas públicas mais inclusivas e eficientes, visto que o conhecimento e as práticas culturais dos atores da sociedade podem ser articulados e/ou negociados com as intenções dos agentes do setor público que estão constituídos nos diversos quadros institucionais, resultando, assim, na valorização das formas de participação e coprodução do espaço público.

Sendo assim, torna-se fundamental a superação dessa dicotomia entre os saberes para que haja uma gestão social de políticas públicas, com o deslocamento das ações dos escritórios das instituições públicas para as bases da sociedade. É preciso, portanto, incentivar a criação de condições que favoreçam uma relação dialógica entre esses dois universos de significações, que é formado, por um lado, pelo saber técnico-científico dos representantes das instituições do setor público e, de outro, pelo saber local ou senso comum da sociedade.

\section{Considerações finais}

De modo geral, pode-se observar que os modelos conceituais tendem a apresentar elementos fundamentais na análise de políticas públicas, segundo diferentes perspectivas. Ao fundamentar a análise de políticas públicas no modelo processual, também chamado de ciclo de políticas públicas, pode-se observar que a sua principal pressuposição está na visão estratégica que reconhece a necessidade do uso das clássicas funções administrativas de planejar, organizar, dirigir e controlar, cujos significados são traduzidos nas etapas de formulação, implementação e avaliação. Ao focar essencialmente nessa visão estratégica, o analista corre o risco de interpretar a política pública como uma mera ação administrativa dividida em etapas e de desconsiderá-la como um produto complexo de forças do contexto político e social. Foi nesse sentido que este trabalho procurou revisitar o ciclo de políticas públicas, mas de modo a apresentar algumas ideias que ampliassem o foco estratégico da análise de políticas públicas, conjugando-o com elementos que reforçam a necessidade de um olhar interdisciplinar nos estudos e na gestão das políticas públicas.

Ao compreender o modelo processual como uma construção política e social, na qual as políticas emergem de um processo interativo entre Estado e Sociedade, este trabalho ressaltou aspectos de diferentes naturezas que não poderão ser desconsiderados no processo devido a sua complexidade, tais como: as instituições, o poder, a fragmentação, a descentralização, a participação social, o saber técnico e o saber local. Além disso, ressalta-se que as reflexões aqui realizadas procuram romper com a ideia de que a análise de políticas públicas abrange apenas preceitos da perspectiva tecnoburocrática,

Página 79 Caderno de Ciências Sociais Aplicadas, Vitória da Conquista/BA, vol. 16, n 27, ano 16, p. 58-85, jan/jun 2019. 
mas, sobretudo, instiga iniciativas de formação da esfera pública e emancipação social, servindo de referência para a gestão social de políticas públicas.

Vale destacar que este trabalho não teve como pretensão o esgotamento da temática apresentada, visto que apenas incita algumas questões que podem ampliar o olhar sob o modelo processual de políticas públicas, o qual não deve centrar apenas na operacionalização de etapas orientadas pela busca da tríade eficiência-eficácia-efetividade, tão propagada pelo foco estratégico de tomada de decisão na administração pública. Outras questões devem ser qualificadas, desdobradas e complementadas por diferentes abordagens da Ciência Política, como também de outras Ciências Humanas - como a Sociologia e Antropologia - ou em um diálogo interdisciplinar entre elas (ROMANO,2009). Sob essa perspectiva, acredita-se que o desenvolvimento de trabalhos empíricos utilizando o ciclo de políticas públicas possa suscitar essas relações interdisciplinares, contribuindo assim para desvendar outras questões.

\section{Referências}

ALCÂNTARA, B. C. S. Reflexões sobre o potencial das políticas públicas democrático-populares locais para estudar possibilidades de um novo organizar. Cadernos Ebape, v. 5, n. 2, jun. 2007.

AZEVEDO, J. A. M. Análise de políticas públicas quanto ao seu design: um estudo de caso. In: ENANPAD, 27., 2003, Atibaia. Anais... Atibaia: ANPAD, 2003. CD-ROM.

ASSUMPÇÃO, J. J.; CAMPOS, L. M. S. Avaliação de projetos sociais: a rede, os nós e a teia. In: ENANPAD, 33., 2009, São Paulo. Anais... São Paulo: ANPAD, 2009. CD-ROM.

BARCELOS, M. A formação da área de análise de políticas públicas: do modelo "racional compreensivo" às abordagens "sintéticas" do processo da política pública. Sociais e Humanas, Santa Maria, v. 26, n. 01, jan/abr 2013, p. 145-162

BEDUSCHI FILHO, L. C.; ABRAMOVAY, R. Desafios para o desenvolvimento das regiões rurais. Nova Economia, Belo Horizonte, v. 14, n. 3, p. 35-70, set./dez. 2004.

BRESSER PEREIRA, L. C. A reforma gerencial do Estado de 1995. Revista de Administração Pública, Rio de Janeiro, v. 34, n. 4, p. 55-72, jul./ago. 2000.

BRESSER PEREIRA, L. C.; GRAU, N. C. (Org.). O público não-estatal na reforma do Estado. Rio de Janeiro: FGV, 1999. p.15-48.

CALMON, P. C. D. P.; COSTA, M. M. Análise de políticas públicas no Brasil: estudos sobre a formação da agenda governamental. In: ENANPAD, 31., 2007, Rio de Janeiro. Anais... Rio de Janeiro: ANPAD, 2007. CD-ROM.

Página 80 Caderno de Ciências Sociais Aplicadas, Vitória da Conquista/BA, vol. 16, n 27, ano 16, p. 58-85, jan/jun 2019. 
CARVALHO, M. A. Uma introdução à análise de políticas públicas: análise custo-benefício, árvores de decisão e modelos de multiatributos. In: ENANPAD, 29., 2005, Brasília. Anais... Brasília: ANPAD, 2005. CD-ROM.

CARLOS, E.; SILVA, M. Z. Associativismo, participação e políticas públicas. Política \& Sociedade, Florianópolis, n. 9, p. 163-194, out. 2006.

CAVALCANTE, P.L.C.; ARRUDA, J.A. Aplicação de modelos qualitativos de análise de políticas públicas: o caso da avaliação da educação superior no Brasil. In: ENANPAD, 40., 2016, Costa Sauípe. Anais... Costa Sauípe: ANPAD, 2016. CD-ROM.

DEPONTI, C. M. Possibilidades teóricas para o estudo da intervenção para o desenvolvimento rural. In:SOBER, 47., 2009, Porto Alegre. Anais... Porto Alegre: SOBER, 2009. CD-ROM.

DOWBOR, L. Democracia econômica. Petrópolis: Vozes, 2010, 130 p.

DYE, T. R. Mapeamento dos modelos de análise de políticas públicas. In: HEIDEMANN, F. G.; SALM, J. F. (Org.). Políticas públicas e desenvolvimento: bases epistemológicas e modelos de análise. Brasília: UNB, 2009. p. 99-129.

FARIA, C. A. P. Idéias, conhecimentos e políticas públicas: um inventário sucinto das principais vertentes analíticas recentes. Revista Brasileira de Ciências Sociais, São Paulo, v. 18, n. 51, p.21-29, fev. 2003.

FAORO, R. Os donos do poder. São Paulo: Globo/Publifolha, 2000. 271 p.

FEDOZZI, L. Orçamento participativo: reflexões sobre a experiência de Porto Alegre. Porto Alegre/Rio de Janeiro: Tomo Editorial/FASE/IPPUR, 1999.

FERNANDES, V.; SAMPAIO, C. A. C. Formulação de estratégias de desenvolvimento baseado no conhecimento local. Revista de Administração de Empresas Eletrônica, v. 5, n. 2, jul./dez. 2006.

FILIPPIM, E. S.; ROSSETTO, C. R. Visões norteadoras de administração pública para o desenvolvimento num contexto regional. In: ENAPG, 2., 2006, Salvador. Anais... Salvador: ANPAD, 2006. CD-ROM.

FREY, K. Políticas públicas: um debate conceitual e reflexões referentes à prática da análise de políticas públicas no Brasil. Planejamento e Políticas Públicas, Brasília, n. 21, p. 211-259, jun. 2000.

GAETANI, F. As políticas de gestão pública e os desafios da coordenação. In: OLIVEIRA, F. B. Política de gestão pública integrada. Rio de Janeiro: FGV, 2008. p. 38-46.

GATTAI, S.; ALVES, L. R. A construção de planos diretores como indutora de política pública integrada. In:ENANPAD, 31., 2007, Rio de Janeiro. Anais... Rio de Janeiro: ANPAD, 2007. CD-ROM.

Página 81 Caderno de Ciências Sociais Aplicadas, Vitória da Conquista/BA, vol. 16, n 27, ano 16, p. 58-85, jan/jun 2019. 
HEIDEMANN, F. G.; SALM, J. F. Políticas públicas e desenvolvimento: bases epistemológicas e modelos de análise. Brasília: UNB, 2009. 338 p.

KELMA, C. M. S. C. K. Subsídios para a elaboração e implementação de políticas públicas com recorte de gênero e raça na agricultura familiar. In:SOBER, 44., 2006, Ribeirão Preto. Anais... Ribeirão Preto: SOBER, 2005. CD ROM.

LOT'TA, G. S. Estilos de implementação: ampliando o olhar para análise de políticas públicas. In: ENCONTRO DE ADMINISTRAÇÃO PÚBLICA E GOVERNANÇA, 3, 2008, Salvador. Anais... Salvador: ANPAD, 2008. CD-ROM.

MAFRA, L. A. S.; NAVES, F. L. Gestão de políticas sociais: a importância das articulações institucionais e setoriais em programas de segurança alimentar e nutricional. Cadernos Ebape, v. 7, p. 35-49, mar. 2009.

MARTES, A. C. B. et al. Modelo de avaliação de programas sociais prioritários. Campinas: Unicamp, 1999.

MARTINS, H. F. Uma teoria da fragmentação de políticas públicas. In: ENANPAD, 28., 2004, Curitiba. Anais... Curitiba: ANPAD, 2004.

MEDEIROS, J. P.; BORGES, D. F. Participação cidadã no planejamento das ações da EMATER-RN. Revista de Administração Pública, Rio de Janeiro, v. 41, n. 1, p. 63-81, jan./fev. 2007.

MENY, Y.; THOENIG, J. C. Las políticas públicas. Barcelona: Ed. Ariel, 1992.

MULLER, P.; SUREL, L. L'analyse des politiques publiques. Paris: Ed. Montchrestien, 1998.

NASCIMENTO, A. R.; ZUQUIM, J. Gestão das políticas de promoção e defesa dos direitos da criança e do adolescente: da tecnicidade à gestão social compartilhada. In: ENANPAD, 33., 2009, São Paulo. Anais... São Paulo: ANPAD, 2009. CD-ROM.

NAVES, F. L. Saberes, poderes e os dilemas das relações socioambientais. Organizações Rurais e Agroindustriais, Lavras, v. 6, n. 2, p. 121-133, jul./dez.2005.

OLIVEIRA, J. A. P. Desafios do planejamento em políticas públicas: diferentes visões e práticas. Revista de Administração Pública, Rio de Janeiro, v. 40, n. 1, p. 273-288, mar./abr. 2006.

OLIVEIRA, V. A. R. Administração pública contemporânea: a busca por um caminho efetivo de participação. In: ENANPAD, 33., 2009, São Paulo. Anais... São Paulo: ANPAD, 2009. CD ROM.

OLIVEIRA, V. C. S.; PEREIRA, J. R.; OLIVEIRA, V. A. R. Os conselhos gestores municipais como instrumentos da democracia deliberativa no Brasil. In: ENANPAD, 32., 2008, Rio de Janeiro. Anais... Rio de Janeiro: ANPAD, 2008. CD-ROM.

Página 82 Caderno de Ciências Sociais Aplicadas, Vitória da Conquista/BA, vol. 16, n 27, ano 16, p. 58-85, jan/jun 2019. 
OLVIEIRA, V.E. As fases do processo de políticas públicas. In: MARCHETTI, V. (Org.) Políticas públicas em debate. São Bernardo do Campo: MP Editora, 2013, p.15-37

PAES DE PAULA, A. P. Por uma nova gestão pública: limites e potencialidades da experiência contemporânea. Rio de Janeiro: FGV, 2005.

PECI, A. Pensar e agir em rede: implicações na gestão das políticas públicas. In:ENANPAD, 24., 2000, Florianópolis. Anais... São Paulo, ANPAD, 2000. CD-ROM.

PIRES, R.R.C. A avaliação da implementação de políticas públicas a partir da perspectiva neoinstitucional: avanços e validade. In: ENANPAD, 26., 2002, Salvador. Anais... Salvador, ANPAD, 2002. CD-ROM.

RAEDER, S. Ciclo de políticas: uma abordagem integradora dos modelos para análise de políticas públicas. Perspectivas em Políticas Públicas, Belo Horizonte, vol. VII , No 13 , p. 121-146, jan/jun 2014

RAULI, F. Monitoramento das políticas públicas de Curitiba: uma avaliação crítica sob a ótica dos indicadores de desenvolvimento sustentável. 2007. 182 p. Dissertação (Mestrado em Organizações e Desenvolvimento)-Centro Universitário Franciscano, Curitiba. 2007.

ROCHA, A. G. P.; CERQUEIRA, P. S. Agricultura familiar e políticas públicas: o caso do Pronaf. In: ENANPAD, 27., 2003, Atibaia. Anais... Atibaia: ANPAD, 2003. CD-ROM.

ROMANO, J.O. Política nas políticas: um olhar sobre a agricultura brasileira. Rio de Janeiro: Edur, 2009.308 p.

RUA, M. G. Análise de políticas públicas: conceitos básicos. Programa de Apoio a Gerência Social no Brasil, BID. 1997.

SANTOS , B. de S. Um discurso sobre as ciências na transição para uma ciência pós-moderna. Estudos Avançados, São Paulo, v. 2, n. 2, p. 46-71, maio/ago. 1988.

SARAIVA, L. A. S.; CAPELÃO, L.G. F. A nova administração pública e o foco no cidadão: burocracia x marketing. Revista de Administração Pública, Rio de Janeiro, v. 34, n. 2, p. 59-77, 2000. p.1-9.

SCALABRIN, A. C. et al. A importância do reconhecimento dos saberes do agricultor familiar para o desenvolvimento rural da Amazônia. In: SOBER, 47., 2009, Porto Alegre. Anais... Porto Alegre: SOBER, 2009. CD-ROM .

SILVA, M. V. D. C.; SILVA, F. C. C. Participar para desenvolver: alternativas além do paradigma hegemônico. In: ENANPAD, 33., 2009, São Paulo. Anais... São Paulo: ANPAD, 2009. CD-ROM

SILVA NETO, A. V.; SERRA, M. A. As políticas de transporte no Paraná: uma análise do Governo Lerner - 1995-2002. Revista Paranaense de Desenvolvimento, Curitiba, n. 113, p.129-145, jul./dez. 2007.

Página 83 Caderno de Ciências Sociais Aplicadas, Vitória da Conquista/BA, vol. 16, n 27, ano 16, p. 58-85, jan/jun 2019. 
SECCHI, L. Análise de políticas públicas: diagnóstico de problemas, recomendação de soluções. São Paulo: Cengage Learning, 2016.

SECCHI, L. Políticas públicas: conceitos, esquemas de análise, casos práticos . São Paulo: Cengage Learning, 2014.

SOUZA, C. Políticas públicas: uma revisão da literatura. Sociologias, Porto Alegre, v. 8, n. 16, p. 20 44. jul./dez. 2006.

SAWHNEY, P., KOBAYASHI, M., TAKAHASHI, M., KING, P.N. Y MORI, H. Participation of Civil Society in Management of Natural Resources. InternationalReview for Environmental Strategies, v. 7, 2007, no1:117-132.

STORINO, G. R. Participação cidadã na gestão pública - dá licença seu doutor? Com a palavra: o povo da favela carioca. In: ENANPAD, 25., 2001, Campinas. Anais... Campinas: ANPAD, 2001. CD-ROM.

TEODÓSIO, A. S. S. Parcerias tri-setoriais em políticas sociais: em busca de modelos explicativos de sua complexidade na esfera pública. In: ENANPAD, 33., 2009, São Paulo. Anais... São Paulo: ANPAD, 2009. CD-ROM.

TENÓRIO, F. G. (Neo)tecnocratas ou (neo)bobos? Eis a questão. Organizações \& Sociedade, Salvador, v. 10, n. 26, p. 107-117, jan./abr. 2003.

TENÓRIO, F. G. Desenvolvimento local. In: TENÓRIO, F. G. (Org.). Cidadania e desenvolvimento local. Ijuí: Unijuí, 2007. 627 p.

TENÓRIO, F. G.; ROZENBERG, J. E. Metodologias participativas, experiências em gestão pública e cidadania. In: ENANPAD, 21., 1997, Rio das Pedras. Anais... Rio das Pedras: ANPAD, 1997. CDROM.

TENÓRIO, F. G.; SARAVIA, E. J. Esforços sobre gestão pública e gestão social. In: MARTINS, P. E. M.; PIERANTI, O. P. (Org.). Estado e gestão pública: visões do Brasil contemporâneo. Rio de Janeiro: FGV, 2007. 340 p.

TENÓRIO, F. G. et al. Critérios para a avaliação de processos decisórios participativos deliberativos na implementação de políticas públicas. In: ENAPG, 3., 2008, Salvador. Anais... Salvador: ANPAD, 2008. CD-ROM.

THOMPSON JR, A. A.; STRICKLAND III, A. J. Planejamento estratégico: elaboração, implementação e execução. São Paulo: Pioneira, 2000. 431 p.

TORRES, M. D. F. Estado, democracia e administração pública no Brasil. Rio de Janeiro: FGV, 2007. 224 p.

Página 84 Caderno de Ciências Sociais Aplicadas, Vitória da Conquista/BA, vol. 16, n 27, ano 16, p. 58-85, jan/jun 2019. 


\section{- CADERNOS de GIÉNCIAS SOCIAIS APLICADAS}

VICENTE, V. M. B. Políticas públicas: uma contribuição sucinta à edificação de um modelo para sua análise. In:ENANPAD, 33., 2009, São Paulo. Anais... São Paulo, ANPAD, 2009. CD-ROM.

VIEIRA, R. E. Novo enfoque da gestão pública sócio-ambiental no Brasil: um estudo sobre as políticas públicas socio-ambientais na administração pública brasileira. Disponível em: <http://www.artigosbrasil.net/art/varios/2112/politica-publica-socioambiental.html>. Acesso em: 14 jul. 2010.

WINKLER, D.R. Modelos: da teoria à prática. In: HEIDEMANN, F. G.; SALM, J. F. (Org.). Políticas públicas e desenvolvimento: bases epistemológicas e modelos de análise. Brasília: UNB, 2009. p. 129-132. 